\title{
Illustrated Review of the Embryology and Development of the Facial Region, Part 3: An Overview of the Molecular Interactions Responsible for Facial Development
}

P.M. Som, A. Streit, and T.P. Naidich

\section{ABSTRACT}

SUMMARY: Parts 1 and 2 of this review discussed the complex morphogenesis of the face. However, the molecular processes that drive the morphology of the face were not addressed. Part 3 of this review will present an overview of the genes and their products that have been implicated in the developing face.

ABBREVIATIONS: $B M P=$ bone morphogenic protein; $F g f=$ fibroblast growth factor; $P D G F=$ platelet-derived growth factor; $S h h=$ sonic hedgehog; $T G F \beta=$ transforming growth factor $\beta$

$\mathbf{P}$ arts 1 and 2 of this review discussed the complex morphogenesis of the face from the earliest closure of the anterior neuropore through the embryologic and fetal facial development to the changes that occur in the facial structure from the neonate to the adult. However, the topic of molecular processes that drive the morphology of the face is ever-emerging in complexity and is mostly foreign to our understanding. Yet, this molecular biology is the basis of vertebrate facial embryology. Part 3 of this review will present an overview of the genes and their products that have been implicated in the developing face. The major source of information regarding these genes comes from experiments that knockout or reduce or, in some cases, increase their presence in specific cell populations at differing times in early embryogenesis. The resulting morphologic changes are then observed. Although these genes can be implicated in facial development, their precise activation pathways and interactions remain mostly unclear. One of the most intriguing aspects of the present research in this field is that it is changing the traditional concepts of early craniofacial embryogenesis.

\section{Complex Multistep Process}

The dynamics of facial development is a multistep process that initiates with the creation of neural crest cells and prechordal mesenchyme, the migration of these cells, their epithelial-mesen-

From the Department of Radiology (P.M.S., T.P.N.), Mount Sinai School of Medicine, New York University, New York, New York; and Department of Craniofacial Development and Stem Cell Biology (A.S.), King's College London, Guy's Campus, London, UK.

Please address correspondence to Peter M. Som, MD, Department of Radiology, The Mount Sinai Hospital, One Gustave Levy Place, New York, NY 10029; e:mail: Peter.Som@MSSM.edu

- Indicates open access to non-subscribers at www.ajnr.org

http://dx.doi.org/10.3174/ajnr.A3453 chymal interactions that control growth, their patterning as they are allocated different cell fates while existing in a field of equivalent cells, the appearance of the facial primordia, and finally the subsequent development of the face. It is the presence of specific genes and the signaling of their gene products that coordinate this growth of the face.

The craniofacial development is unique from the rest of the body. First, the cranial neural crest cells give rise to skeletal structures unlike neural crest cells in the rest of the body. Second, with the exception of the tongue, which is formed from segmented somites as are the remaining muscles in the body, the craniofacial muscles are formed from prechordal mesenchyme and unsegmented paraxial mesoderm. ${ }^{1,2}$ The prechordal mesenchyme arises from the prechordal plate immediately anterior to the tip of the anterior notochord. Francis-West et $\mathrm{al}^{1}$ in their detailed review of craniofacial development said, "The prechordal plate is the head organizer region. It lies directly under the developing forebrain and is essential for normal dorsal-ventral patterning of the brain and the subsequent appropriate development of the midline face" (Fig 1). Last, the craniofacial region has neurogenic placodes that are present only in the craniofacial region. These placodes give rise to the lens; inner ears; the olfactory epithelium; and neurons in the trigeminal, facial, glossopharyngeal, and vagal ganglia (epibranchial placodes). ${ }^{3}$

\section{Early Development of the Craniofacial Region}

In the early second embryonic week, the embryoblast begins to differentiate into 2 different cell layers. The epiblast layer develops first, and most of these cells will remain in this layer to become the embryo proper. In the late second to early third embryonic week, a new layer of cells begins to emerge underneath the epiblast (Fig 2 ), the hypoblast (or primitive endoderm). The hypoblast will 


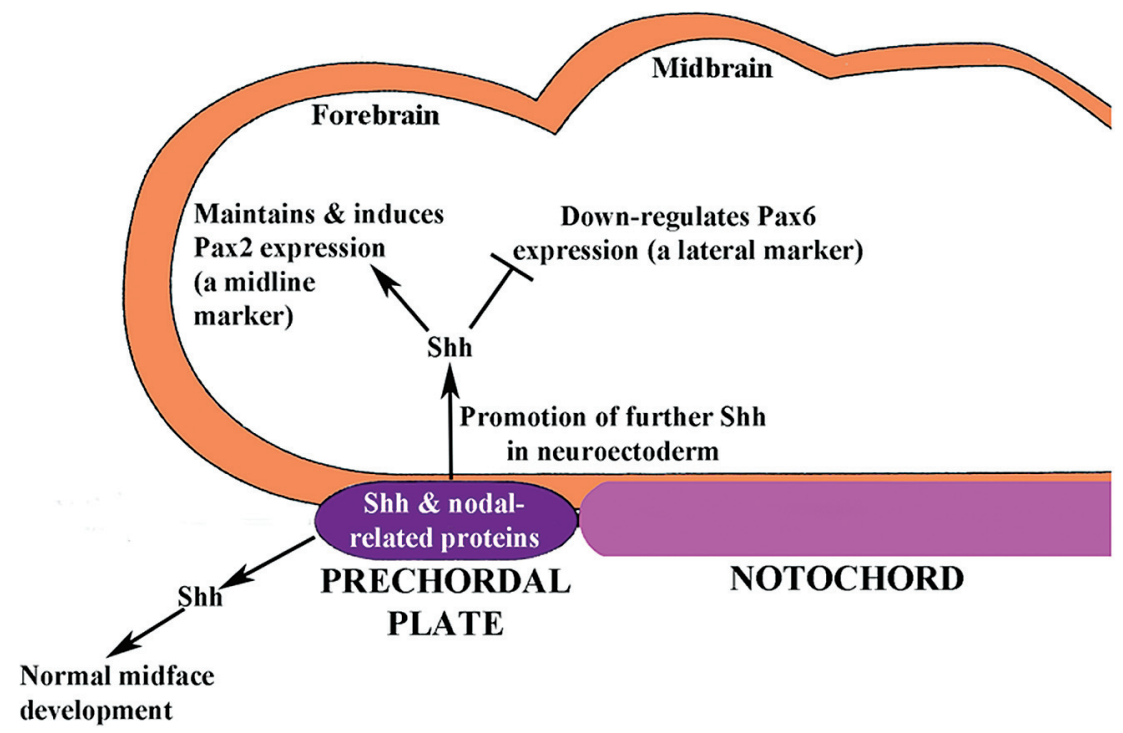

FIG 1. Sagittal diagram shows the craniofacial region and the relationship of the prechordal plate to the ventral notochord. Also shown is some of the signaling that originates in the prechordal plate to influence the optic field division and some of the signaling for normal midfacial development. (Modified from Fig 3, Francis-West PH, Robson L, Evans DJ. Craniofacial development: the tissue and molecular interactions that control development of the head. $A d v$ Anat Embryol Cell Biol 2003;169:III-VI, 1-138. With permisison from Springer Science+Business Media.)

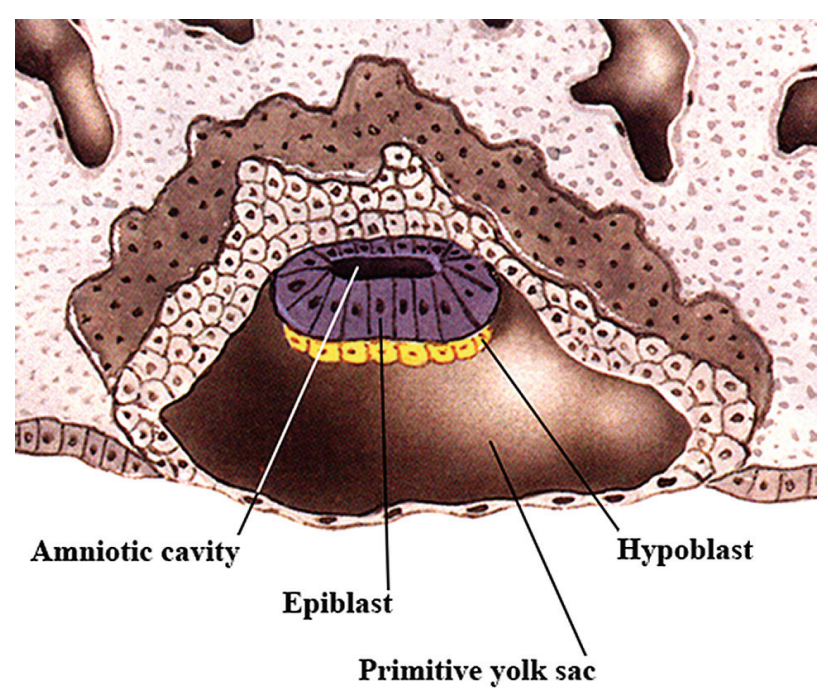

FIG 2. Sagittal drawing of a late 2-week-old embryo showing the embryonic disk with an epiblast layer and a the hypoblast below it. This is the bilaminar embryo just before gastrulation. (Modified with permission from Netter Illustration from www.netterimages.com. Elsevier Inc. ๑ All rights reserved. ${ }^{16,17}$ )

generate extraembryonic tissues, and one of its initial roles is to inhibit primitive streak formation. This early inhibition prevents future mesendodermal cells (cells that can give rise to both endoderm and mesoderm) from premature ingression (migration) below the epiblast layer, while ensuring that future ectodermal cells remain in the epiblast and do not ingress at all. In addition, this early inhibition helps to separate mesendodermal and neuroectodermal cells (cells that will eventually give rise to the central and peripheral nervous systems); the hypoblast also transiently induces expression of preneural markers in the epiblast. Next, in the early third week, the hypoblast controls epiblast cell movement that leads to the formation of the primitive streak, the first obvious morphologic feature that develops in the embryonic disk. ${ }^{4}$ The presence of the primitive streak establishes bilateral symmetry in the embryo and marks the site of gastrulation, which is the process by which the hypoblast forms only extraembryonic tissues and the epiblast layer is converted into a trilaminar disk with all 3 germ layers. Shortly after the primitive streak is first visible, the primitive groove appears along its midline (Fig 3A).

Soon after primitive streak formation, the primitive node arises at its anterior end along with the primitive pit, a depression developing along the dorsal aspect of the node, which is continuous posteriorly with the primitive groove (Fig $3 B$ ). "Ingression" is the movement of cells through the primitive streak: Starting in the mid-third week, epiblast cells move into the streak and fan outward to become mesoderm or endoderm under the epiblast. Cells ingressing at different positions along the anteroposterior length of the streak contribute to different mesodermal tissues. Those cells that migrate anteriorly via the primitive pit in the midline will form the axial mesoderm, the prechordal plate, and notochord (Fig 4). Precursors for both structures are initially intermixed but segregate eventually. Cells that ingress in the lateral node also participate in notochord formation and contribute to the medial portions of the somites (the paraxial mesoderm), while cells ingressing just posterior to the node form the lateral somites. Cells that move through the more posterior parts of the streak form the intermediate, lateral plate, and extraembryonic mesoderm, respectively. Thus, mesodermal cells with different ultimate fates are organized along the anteroposterior axis of the primitive streak: Axial precursors lie at its most rostral end, and lateral precursors, caudally. Once the primitive streak has reached its full length, it begins to regress posteriorly while ingression continues, and in its wake, it lays down the body axis. The primitive node is eventually absorbed into the tail bud.

As gastrulation occurs, the neural plate is induced by signals from the primitive node. Its appearance is the first morphologic manifestation of the forming central nervous system, and during neurulation, it will eventually form the neural tube and give rise to the brain and spinal cord.

In summary, during gastrulation, a trilaminar disk is formed with the epiblast cells that remain at the surface becoming the ectoderm, cells that ingress and replace the hypoblast becoming the endoderm, and the cells between these layers becoming the mesoderm. Table 1 gives an overview of events that lead to the formation of the trilaminar embryo. However, most of these processes are fluid and merge into each other, and some happen at the same time. After gastrulation, the remains of the hypoblast may protect some prospective forebrain cells from caudalizing signals, 

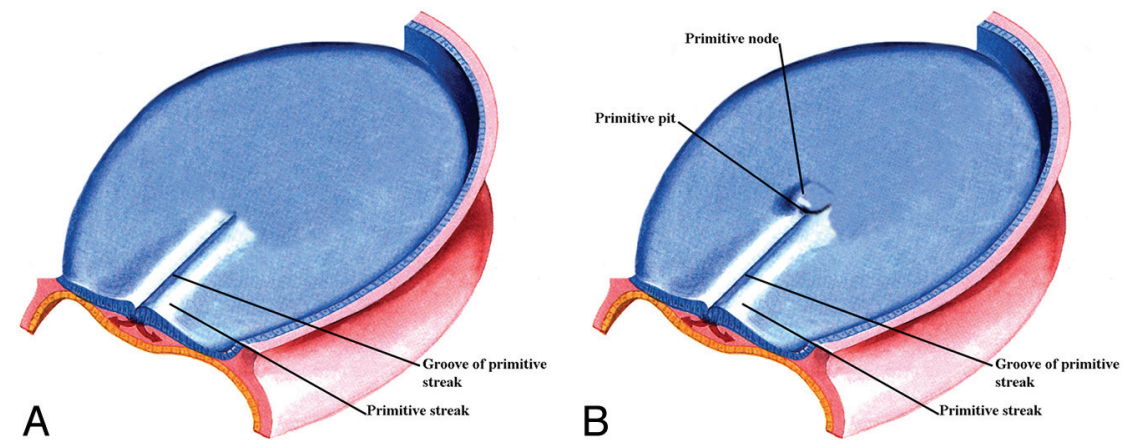

FIG 3. A, Oblique view from above of an early 3-week embryo shows the appearance of the primitive streak. Within the center of the primitive streak, a groove develops. Modified with permission from Cochard ${ }^{17}$ and Netter et al. ${ }^{18} B$, Oblique view from above of an embryo a few days older than that in Fig $3 A$ shows the development of the primitive node and the primitive pit at the ventral margin of the primitive streak. (Modified with permission from Netter Illustration from www.netterimages.com. Elsevier Inc. @ All rights reserved. ${ }^{16,17}$ )

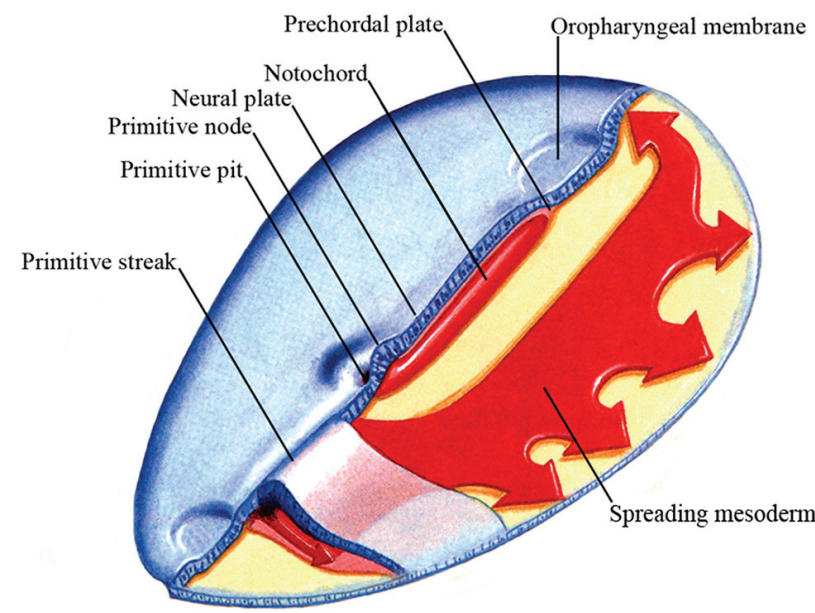

FIG 4. Oblique view from above of an embryo slightly older than that in Fig $3 B$ showing the relative relationship of the neural plate, prechordal plate and notochord, primitive streak, and primitive node. Also shown is the mesoderm spreading out under the epiblast. (Modified with permission from Netter Illustration from www.netterimages.com. Elsevier Inc. ๑ All rights reserved. ${ }^{16,17}$ )

Table 1: Summary of the order of development of the trilaminar embryonic disk

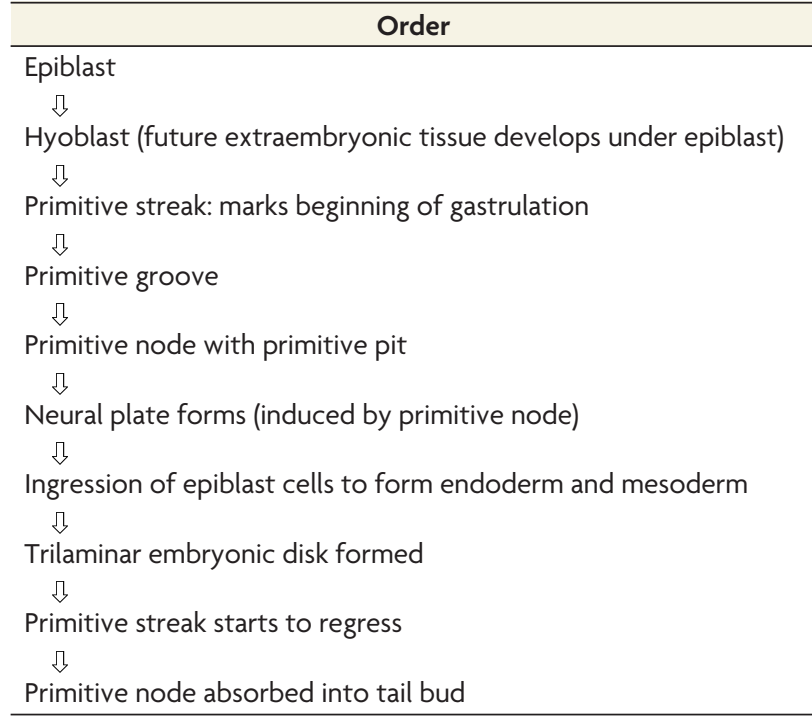

which would otherwise confer a posterior identity to neural tissue to generate midbrain or hindbrain.

\section{Formation of the Placodes}

The placode precursors are induced at the edge of the anterior neural plate and then segregate into the cells with individual placode identities. By early gastrulation, this ectodermal border zone expresses both neural and non-neural markers. Within this zone, precursors for 4 cell populationsneural, neural crest, epidermal, and placode cells-are initially intermingled but segregate later through patterning events (Fig 5). With respect to placode formation, members of the Six and Eya families of nuclear factors are key players and become expressed in this border zone, where the precursors for all placodes become concentrated. This region is now called the "preplacodal territory" or "zone." Although the cells in the preplacodal zone are initially competent to form any placode, soon the placode precursors seem to acquire different regional characteristics as evidenced by differential gene expression. For example, Pax6, Six3, and Otx2 are confined to anterior placode cells, while $I r x 1 / 2 / 3$ and $G b x 2$ are found posteriorly. By the early somite stage, Pax6 is concentrated in the cells that will give rise to the olfactory and lens placodes, while Pax 3 and Pax2/8 are located in cells that will develop into the trigeminal, otic, and epibranchial placodes, respectively. ${ }^{5}$

In the early border zone, the decision of the multipotential cells to evolve into either neural crest cells or preplacodal cells is controlled by modulation of signals from the surrounding tissues. As discussed in the next paragraphs, signals from the head mesoderm provide antagonists to both $B M P$ and $W n t$ that protect placode precursors from inhibitory influences, allowing them to develop. However, signals from the neural folds trigger neural crest development, and unlike the preplacodal zone, interaction between the neural plate and the ectoderm is sufficient to induce neural crest cells. ${ }^{6}$

During gastrulation, BMPs induce a set of factors that make the ectoderm competent to become placode precursors. In this context, competence means that a tissue can respond to an inducing signal from outside the cell, causing it to change its fate. These competence factors are important for the expression of Six and Eya genes as discussed above. Shortly thereafter BMP signaling must be completely blocked (during the late second and early third weeks) by antagonists to induce preplacodal rather than neural crest identity in cells bordering the neural plate. ${ }^{6}$ This blocking is important because the preplacodal zone is surrounded by inhibitory signals from the ectoderm laterally $(B M P)$ and posteriorly $(W n t)$, from the neural folds medially ( $W n t$ and $B M P$ ), and from the lateral and posterior mesoderm $(W n t)$. Both $W n t$ and BMP antagonists from the mesoderm underlying the preplacodal region protect the overlying ectoderm from these inhibitory signals, allowing the formation of the placodal precursors. ${ }^{5}$ Once placode precursors have formed, members of the fibroblast growth factor family of signaling molecules together with other signals play an important role, causing the emer- 


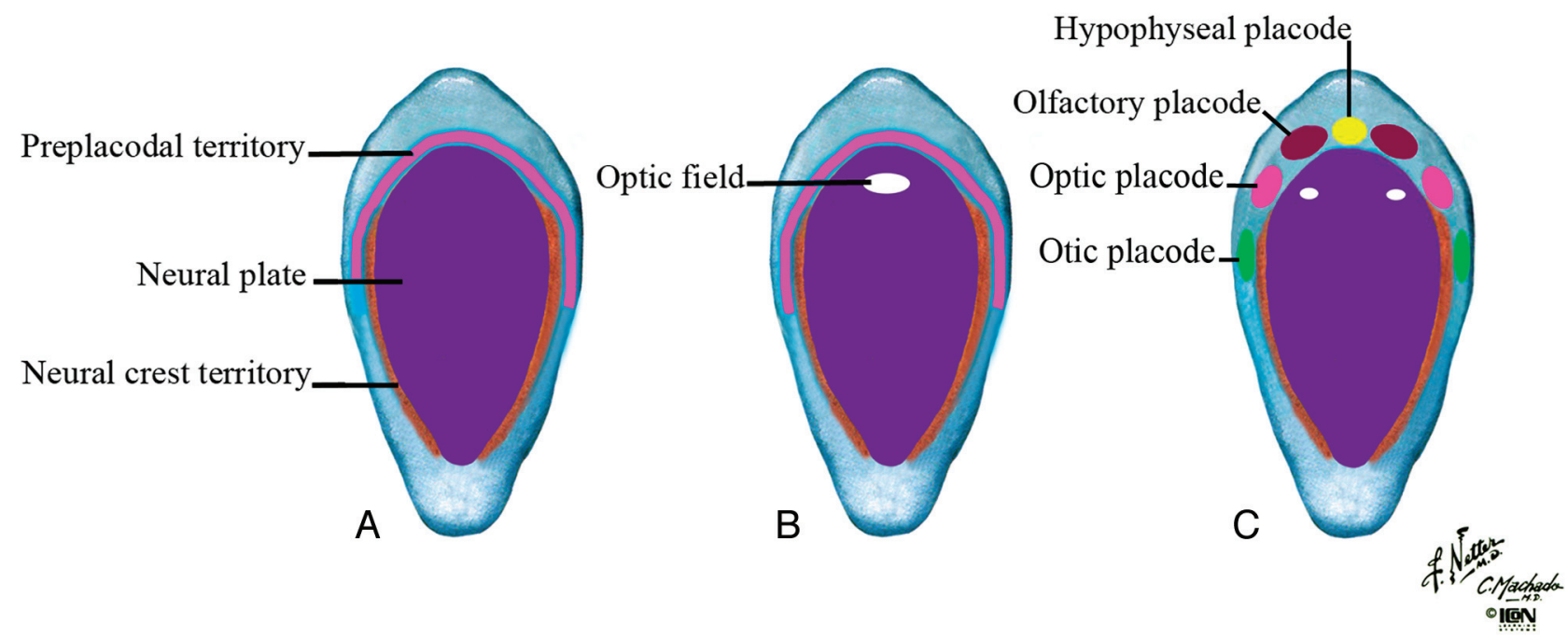

FIG 5. $A$, Location of the preplacodal territory and $(B)$ the region around the anterior neural plate. The optic field develops to eventually be divided by signals from the prechordal plate. $C$, The placodes have separated from the preplacodal territory. (Modified with permission from Netter Illustration from www.netterimages.com. Elsevier Inc. ๑ All rights reserved. ${ }^{16,17}$ )

\section{Table 2: Summary of the order of development of the placodes}

\section{Order}

Early in gastrulation, ectodermal cells around the future neural plate express both neural and non-neural markers

ת

Six and Eya nuclear markers begin to be expressed after neural plate formation at its border; precursors for all placodes concentrate in the Six- and Eya-expressing territory ת

Pax6, Six3, Otx2 expression is concentrated anteriorly

$\operatorname{Ir} \times 1 / 2 / 3, G b \times 2$ expression is concentrated posteriorly

ת

Signaling molecules (including Fgfs) from surrounding tissue induce the formation of the individual placodes

Table 3: Factor and receptor families known to play roles in placode induction

\begin{tabular}{lllllll}
\hline \multicolumn{1}{c}{ Placode } & \multicolumn{5}{c}{ Inducer Families } \\
\hline Adenohypophysis & FGF & PDGF & RA & Shh & TGF $\beta$ family & Wnt $^{\text {a }}$ \\
Lens & FGFR & & & Shh & Nodal, BMP4 & \\
Olfactory & FGF & & & & & \\
Otic & FGFR & & & & Wnt \\
& FGF & & & & \\
Epibranchial & FGFR & & & & \\
(VII, IX, X) & FGF & & & & \\
Trigeminal & FGF & PDGF & & \\
& & PDGFR & & \\
\hline
\end{tabular}

Note:- RA indicates retinoic acid; $P D G F R$, platelet-derived growth factor receptor; FGFR, fibroblast growth factor receptor; $P D G F$, platelet-derived growth factor.

${ }^{a}$ Modified from Table 2 in McCabe KL, Bronner-Fraser M. Molecular and tissue interactions governing induction of cranial ectodermal placodes. Dev Biol 2009;332:189-95, Elsevier Inc. ๑ All rights reserved. ${ }^{3}$

gence of the individual placodes. Different members of the family are responsible for inducing unique characteristics of each placode from the preplacodal territory. ${ }^{5}$ Table 2 summarizes the events that lead to the formation of the placodes, and Table 3 shows the current understanding of the factors and receptors that are implicated in induction of the placodes.

\section{Craniofacial Development and Normal Neural Development}

Current thinking is that initially there are common precursors for the central nervous system, neural crest, and the placodes. With time, these precursors are exposed to different signals and they acquire distinct characteristics. Thus, the embryonic development of the craniofacial region is dependent on normal neural development. Thus, rostral-caudal patterning abnormalities of the neural crest will cause facial abnormalities because this neural crest gives rise to facial skeletal structures and the connective tissues of the face. Signaling from the prechordal plate mesoderm is required for normal development of the ventral diencephalon, which divides the eye (retinal) field into 2 components ${ }^{7}$ - that is, prechordal plate signaling promotes Pax2 and inhibits Pax6 expression to promote division of the single optic field. One of the key signals mediating this process is $S h h$, which is expressed in the axial mesoderm and the prechordal plate. It promotes $P a x 2$ and inhibits Pax6 expression (Fig 1). ${ }^{8}$ If prechordal signaling is interrupted, a single midline eye is formed and there is a resulting cyclops (Fig 5). The neural crest and its related gene products are also essential for normal patterning of the craniofacial region.

Initially the developing face consists of the medial and lateral maxillary processes that together will form the upper jaw and the mandibular processes that will give rise to the lower jaw. The mesenchymal cells that form these processes are of neural crest origin. It is the coordinated outgrowth of these primordia and their ultimate fusion that is essential for the development of a normal face. In the beginning, these primordia consist of undifferentiated neural crest-derived mesenchyme covered by a layer of ectoderm. The control of these outgrowths is by epithelial- 


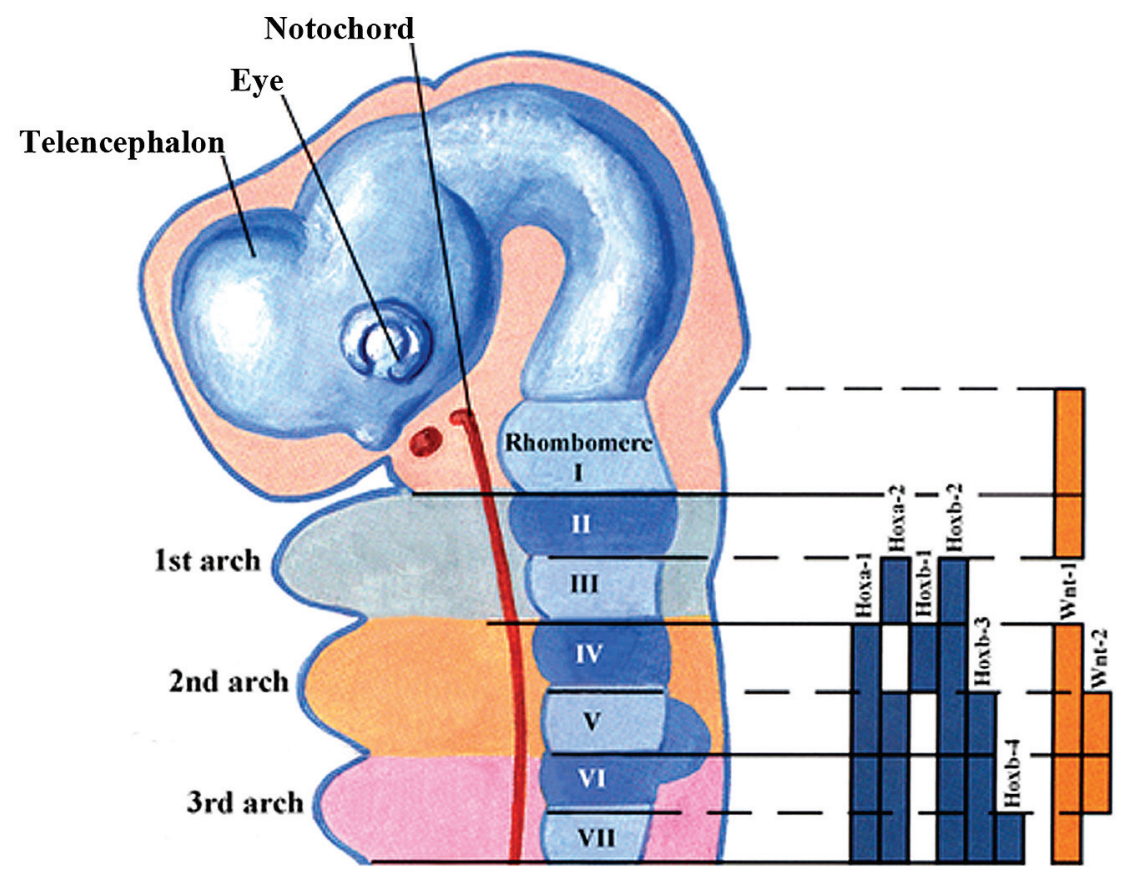

FIG 6. Sagittal drawing illustrating the Hox gene family signaling in the hindbrain and the pharyngeal arches. The solid bars represent the Hox gene expression in the neural crest cells and the neural tube. The downregulation of the Hoxa-2 gene in the first arch of neural crest cells is necessary for normal first arch development. (Modified with permission from Netter Illustration from www.netterimages.com. Elsevier Inc. ๑ All rights reserved. ${ }^{16,17}$ )

Table 4: Summary of factors related to facial abnormalities discussed in the text

\begin{tabular}{|c|c|}
\hline Factor & Some Observed Abnormalities \\
\hline RA & $\begin{array}{l}\text { Excess leads to fusion of 1st and 2nd branchial arches and acoustic- } \\
\text { facial ganglia, small jaws, cleft palate, deformed pinna (Treacher- } \\
\text { Collins syndrome); RA controls Shh and Fgf8 levels }\end{array}$ \\
\hline Fgf & $\begin{array}{l}\text { Controls outgrowth of facial primordia and migration of neural (Fgf) } \\
\text { crest cells to facial processes; a decrease in FBGFRI leads to midline } \\
\text { clefting and Kallmann syndrome, small face and skull, achondroplasia, } \\
\text { Crouzon syndrome, Apert syndrome }\end{array}$ \\
\hline TGF & $\begin{array}{l}\text { TGF } \beta \text { required for fusion of lateral palatal processes; a decrease leads } \\
\text { to defects in maxillary and mandibular development }\end{array}$ \\
\hline$B M P$ & $\begin{array}{l}\text { A decrease leads to short frontal and nasal bones and small pterygoid } \\
\text { processes, short stature, ear defects, odontogenic patterning } \\
\text { defects, slower neural tube closure, small branchial arches, loss } \\
\text { of incisor teeth }\end{array}$ \\
\hline Shh protein & $\begin{array}{l}\text { A decrease leads to holoprosencephaly, hypotelorism; an increase leads } \\
\text { to a wide forehead, frontonasal dysplasia, Gorlin syndrome, Grieg } \\
\text { cephalopolysyndactyly, Smith-Lemli-Opitz syndrome }\end{array}$ \\
\hline Whts & $\begin{array}{l}\text { A decrease leads to loss of teeth, truncation of jaw, mesencephalic } \\
\text { nucleus, and trigeminal nerve }\end{array}$ \\
\hline$E T-1$ & $\begin{array}{l}\text { A decrease leads to aplasia of 1st and 2nd arches, defects in maxilla and } \\
\text { cleft palate, malformations of middle and external ear; 22q11.2 } \\
\text { deletion syndrome (CATCH22 syndrome) }\end{array}$ \\
\hline Jagged 1 and 2 & $\begin{array}{l}\text { A decrease leads to Alagille syndrome, failure of palatal shelves to } \\
\text { elevate, and fusion of shelves with tongue }\end{array}$ \\
\hline $\begin{array}{l}\text { Platelet-derived } \\
\text { growth factors }\end{array}$ & A decrease leads to loss of some facial bones \\
\hline $\begin{array}{l}\text { Homeobox- } \\
\text { containing genes }\end{array}$ & $\begin{array}{l}\text { A decrease leads to primitive facial morphology, cleft palate, short } \\
s \text { maxilla and mandible, loss of maxillary molar teeth, ankyloglossia }\end{array}$ \\
\hline
\end{tabular}

Note:-RA indicates retinoic acid; FGFR, fibroblast growth factor receptor; PDGFR, platelet-derived growth factor receptor.

mesenchymal interactions, and it is primarily the mesenchymal signaling that controls the outgrowth. ${ }^{9}$ In addition to retinoic acid, 5 key families of secreted growth factors have been identified that control facial outgrowth via regulation of cell proliferation and survival. These factors include fibroblast growth factors, transforming growth factor $\beta$ and bone morphogenetic proteins, sonic hedgehog, Wnts, and endothelin-1 (ET-1). Last, there are the contributions of jagged 1 and 2, platelet-derived growth factors, and homeobox-containing genes (Fig 6). Table 4 summarizes the effect of these factors on facial development. It may be that each region of the head can be viewed as a distinct module with its own unique set of signaling interactions. ${ }^{1,10}$

\section{Coordinated Growth-Factor Signaling}

As can be surmised from the preceding paragraphs, these gene and gene products do not act alone. For normal facial growth and patterning, signaling of multiple growth factors must be highly coordinated. Thus as an example, expression of $E T-1$ is dependent on Fgf 8 function in some regions of the facial primordial. On the other hand, antagonistic signaling interactions between F $f 8$ and BMP4 outline the boundaries of gene expression for a number of homeobox-containing genes, and this can determine the position of the odontogenic field and odontogenic patterning. ${ }^{1,9}$ In addition, retinoic acid, Fgf, and $B M P$ are responsible for controlling Shh and overall facial outgrowth. ${ }^{11}$ In general, signaling is subject to precise spatial and temporal control: Too much or too little genetic input or input out of the regulated normal temporal sequence results in abnormalities. ${ }^{12}$

As an example of the multivariant signaling and its temporal organization needed for normal development, the following are some of the genetic factors required for correct palatal shelf formation and fusion. For initial budding of the palatal shelf, Fgf-Shh signaling needs to be coordinated. Jagged-2, the paired box gene 9 , serotonin, and hyaluronan are required for palatal shelf formation and elevation. Poliovirus receptor-related 1 and TGF $\beta 3$ are expressed in the palatal shelf medial edge epithelium, while the homeobox proteins $L h x-8$ and $M s x-1$ are expressed in the underlying mesenchyme. TGF $\beta 3, T G F-\alpha$, and epidermal growth factor are required for the breakdown of the medial edge epithelium. In addition, derivatives of $\gamma$-aminobutyric acid signaling are critical to palatal formation, and loss of $\gamma$-aminobutyric 

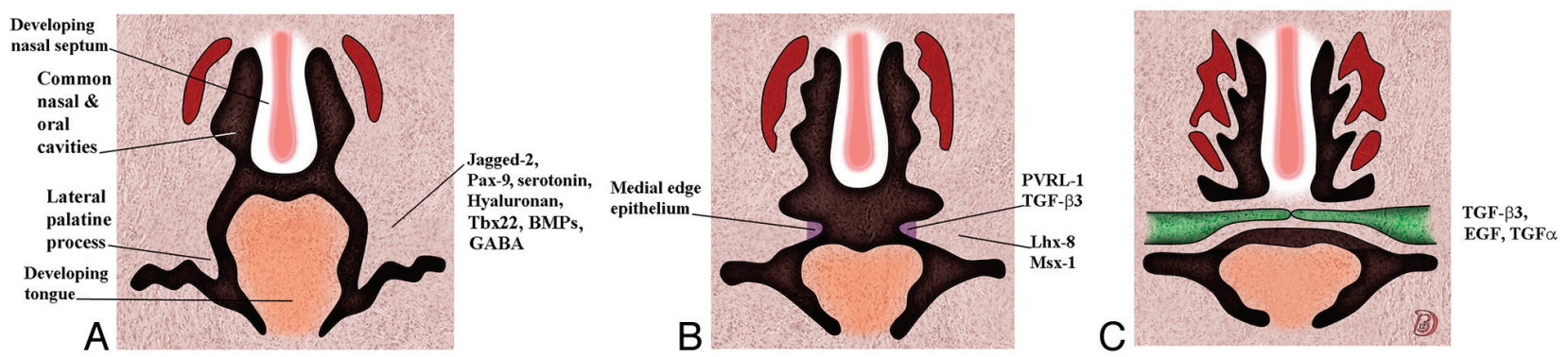

FIG 7. Serial coronal drawings showing the development of the palate and the genes associated with the stages of this development. $A$, The lateral palatal shelves emerge. B, The palatal shelves have elevated. C, The shelves have met in the midline, the medial edge epithelium dissolves, and the shelves eventually fuse.

Table 5: Gene mutations associated with cleft palate in humans ${ }^{\mathrm{a}}$

\begin{tabular}{|c|c|}
\hline Genes & Associated Conditions \\
\hline Collagen genes, $C O L I I$ and $X I$ & $\begin{array}{l}\text { Otospondylomegaepiphyseal dysplasia, } \\
\text { achondrogenesis type II, } \\
\text { Stickler syndrome types I-III }\end{array}$ \\
\hline $\begin{array}{l}\text { Diastrophic dysplasia sulfate } \\
\text { transporter }\end{array}$ & Diastrophic dysplasia \\
\hline FGFR2 & Apert syndrome \\
\hline Homeobox MSX1 & Cleft palate and hypodontia \\
\hline TGF $\beta$ Rl or TGF $\beta R 2$ & $\begin{array}{l}\text { Aortic aneurysm, arterial tortuosity, hypertelorism, } \\
\text { cleft palate, bifid uvula, craniosynostosis }\end{array}$ \\
\hline$T-B \circ \times 1(B X I)$ & DiGeorge/Velo cardiofacial syndrome \\
\hline T-Box $22(T B X 22)$ & X-linked cleft palate and ankyloglossia \\
\hline TCOFI & Treacher Collins syndrome \\
\hline TWIST & Saethre-Chotzen syndrome \\
\hline
\end{tabular}

Note:-FGFR2 indicates fibroblast growth factor receptor 2.

a Other genes and proteins associated with normal palatal formation include the following: Fgf-Shh signaling, Tbx22, BMPs, Jagged-2, Pax-9, serotonin, hyaluronan, PVRL1, TGF- $\beta 3$, TGF- $\alpha$, EGF, Lhx-8, Msx-7, and GABA (Fig 1). Table modified from Rice DP. Craniofacial anomalies: from development to molecular pathogenesis. Curr Mol Med 2005; 5:699-722, Table 2, @ Bentham Science Publishers. ${ }^{16}$

Table 6: Gene mutations associated with cleft lip/cleft palate in humans $^{\mathrm{a}}$

\begin{tabular}{ll}
\multicolumn{1}{c}{ Gene } & \multicolumn{1}{c}{ Condition } \\
\hline DHCR7 & Smith-Lemli-Opitz syndrome \\
EFNB1 & Craniofrontonasal syndrome \\
FGFR1 & Kallmann syndrome \\
IRF6 & van der Woude syndrome \\
OFD1 & Oral-facial-digital syndrome type I \\
MID1 & Opitz syndrome \\
MSX1 & Cleft lip/palate with hypodontia \\
PVRL1 & Margarita Island ectodermal dysplasia (part of cleft \\
& lip/palate-ectodermal dysplasia syndrome) \\
TP73 L (p63) & Ectrodactyly, ectodermal dysplasia, and cleft \\
& lip/palate, ankyloblepharon-ectodermal \\
& dysplasia-clefting syndrome \\
SIX3 & HPE2 \\
TGIF & HPE4 \\
PTCH1 & HPE7 \\
GLI2 & HPE-like features
\end{tabular}

Note:-HPE indicates holoprosencephaly.

a Table modified from Rice DP. Craniofacial anomalies: from development to molecular pathogenesis. Curr Mol Med 2005;5:699-722, Table 1, ๑ Bentham Science Publishers. $^{16}$

acid signaling increases the risk of a cleft palate. Both excess and loss of retinoids also may result in a cleft palate. The formation of the palate is summarized in Fig 7. Tables 5 and 6 list some of the gene mutations associated with a cleft palate with and without a cleft lip in humans. ${ }^{1,9}$

If any of the above normal signaling does not occur, a cleft palate can occur either as an isolated entity or in combination with a cleft lip, and there are $>300$ syndromes in which such clefts are associated-that is, clefts occur when there are abnormalities in the normal process of development.

From the above discussion, it is clear that multiple genes and precise temporal occurrence are necessary for normal palatal development. Additional considerations are anteroposterior gradients and medial-lateral spacial gradients of gene products. This is especially evident along the fusion line of the lateral palatal shelves. Thus, Osr1 and Ors2 are expressed in a medial-lateral gradient in the palatal shelves, and loss of Ors2 retards shelf elevation. Similarly, fibroblast growth factor receptor 2 (Fgfr2) is concentrated in the medial aspect of the palatal shelf, suggesting that it plays a role in palatal elevation. Genetic heterogeneity is also noted along the anteroposterior axis with, as an example, $F g f 8$ signaling selectively inducing expression of $\operatorname{Pax} 9$ in the posterior palatal mesenchyme.

Ossification of the palate is also under genetic control. As an example, Sox9 controls cartilage development and blocks the expression of Runx2, a transcription factor essential for normal osteoblast differentiation and bone formation. If Sox 9 is mutant, Run $x 2$ expression is not repressed and ossification of the palatal shelves occurs too early. Because they are prematurely ossified, they cannot grow together in the midline and a cleft palate results.

Similar rostral/caudal and medial/lateral segregation of genetic products occurs in almost all facial developmental regions. This is also especially noted in the development of the mandible primordia where ET-1, BMP4, FGF-8, and Dix3 are rostral, while Gsc, Msx1, Msx2, Barx1, Pax9, and Lhx6 are caudal. ${ }^{1}$

\section{How Does Signaling Affect the Cell?}

The various signaling mentioned above needs a means of affecting specific cells to accomplish their programmed mission, and there is a variety of methods of cell communication that can occur. These proteins can be considered as external signals in the environment of the cells, and the signals may come from a number of sources, which include the following: a cell signaling to itself (autocrine), a nearby cell in the microenvironment (paracrine), from 
a distant cell (hormones), or interactions of surface-specific signaling molecules. When one considers signaling molecules, there are 2 main types: those that diffuse into the cell and bind directly to internal receptors (steroids, retinoids [vitamin A]) and those signaling molecules that are called ligands and bind to the extracellular receptor component of a transmembrane protein. While the extracellular component of the transmembrane protein binds a specific signaling molecule, the intracellular portion in the cytosol of the cell activates proteins that eventually, via a variety of pathways, regulate gene transcription in the nucleus. ${ }^{13,14}$

\section{CONCLUSIONS}

The purpose of this review was to give some insight into the complex world of molecular products and their interactions as they participate in the embryogenesis of the face. There is rarely only 1 gene that is responsible for a morphologic change. What is starting to be defined is a complex regulatory network that controls these events; and within this network, each step in the temporal hierarchy can be identified by a specific set of transcription factors that cross-regulate each other and that, in turn, are controlled by defined signaling inputs. ${ }^{15}$ Thus, facial patterning is controlled by complex and coordinated signaling between the mesenchyme and epithelium. However, the precise roles of these tissues remain incompletely understood. How neural crest cells influence gene expression in the epithelium once they have reached the facial primordia is just beginning to be understood. How patterning between different neural crest cell populations is coordinated and how patterning is related to cell differentiation are presently being intensely studied. Although many of the genes that control facial development are known, how these genes interact and how their malfunction influences cellular behavior are mostly unclear. Once these and other remaining questions are answered and there is a more complete understanding of the molecular changes involved in normal facial development, how and why facial malformations occur and how they may possibly be prevented will be better understood. ${ }^{1,9,10}$

\section{REFERENCES}

1. Francis-West PH, Robson L, Evans DJ. Craniofacial development: the tissue and molecular interactions that control development of the head. Adv Anat Embryol Cell Biol 2003;169:III-VI, 1-138

2. Osumi-Yamashita N. Retinoic acid and mammalian craniofacial morphogenesis. J Biosci 1996;21:313-27

3. McCabe KL, Bronner-Fraser M. Molecular and tissue interactions governing induction of cranial ectodermal placodes. Dev Biol 2009; 332:189-95

4. Stern CD, Downs KM. The hypoblast (visceral endoderm): an evodevo perspective. Development 2012;139:1059-69

5. Streit A. The preplacodal region: an ectodermal domain with multipotential progenitors that contribute to sense organs and cranial sensory ganglia. Int J Dev Biol 2007;51:447-61

6. Litsiou A, Hanson S, Streit A. A balance of FGF, BMP and WNT signalling positions the future placode territory in the head. Development 2005; 132:4051-62

7. Li H, Tierney $\mathrm{C}$, Wen $\mathrm{L}$, et al. A single morphogenetic field gives rise to two retina primordia under the influence of the prechordal plate. Development 1997;124:603-15

8. Macdonald $\mathrm{R}$, Barth $\mathrm{KA}, \mathrm{Xu} \mathrm{Q}$, et al. Midline signalling is required for Pax gene regulation and patterning of the eyes. Development 1995; 121:3267-78

9. Rice ME, Lee EJ, Choy Y. High levels of ascorbic acid, not glutathione, in the CNS of anoxia-tolerant reptiles contrasted with levels in anoxia-intolerant species. J Neurochem 1995;64:1790-99

10. Kim CH, Park HW, Kim K, et al. Early development of the nose in human embryos: a stereomicroscopic and histologic analysis. $\mathrm{La}$ ryngoscope 2004;114:1791-800

11. Liu B, Rooker SM, Helms JA. Molecular control of facial morphology. Semin Cell Dev Biol 2010;21:309-13

12. Yu W, Serrano M, Miguel SS, et al. Cleft lip and palate genetics and application in early embryological development. Indian J Plast Surg 2009;42(suppl):S35-50

13. Kimball JW. Biology. St. Louis: William C. Brown; 1994

14. Naidich TP, Blaser SI, Lien RJ, et al. Embryology and congenital lesions of the midface. In: Som PM, Curtin HD, eds. Head and Neck Imaging. Philadelphia: Elsevier; 2011:3-97

15. Grocott T, Tanbalo M, Streit A. The peripheral sensory nervous system in the vertebrate head: a gene regulatory perspective. $\mathrm{Dev}$ Biol 2012;370:3-23

16. Rice DP. Craniofacial anomalies: from development to molecular pathogenesis. Curr Mol Med 2005;5:699-722 